\title{
Proton NMR Spectroscopy of Cerebral Metabolic Alterations in Infantile Peroxisomal Disorders
}

Article in Journal of Computer Assisted Tomography · May 1992

DOI: 10.1097/00004728-199205000-00001 · Source: PubMed

CITATIONS

87

7 authors, including:

\section{Harald Bruhn}

Friedrich Schiller University Jena 163 PUBLICATIONS 6,813 CITATIONS

SEE PROFILE

\section{G. Christoph Korenke}

Klinikum Oldenburg

114 PUBLICATIONS 2,419 CITATIONS

SEE PROFILE

\section{READS}

13

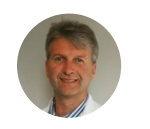

Bernd Kruse

HELIOS Kliniken

44 PUBLICATIONS $\quad \mathbf{1 , 5 7 3}$ CITATIONS

SEE PROFILE

Jens Frahm

Max Planck Institute for Biophysical Chemi...

556 PUBLICATIONS 26,532 CITATIONS

SEE PROFILE

Some of the authors of this publication are also working on these related projects:

Neuroscience-autoimmune View project

Project $\quad$ IMRI-based neurofeedback View project

All content following this page was uploaded by Jens Frahm on 09 February 2016. 


\title{
Proton NMR Spectroscopy of Cerebral Metabolic Alterations in Infantile Peroxisomal Disorders
}

\author{
Harald Bruhn, Bernd Kruse, Georg Christoph Korenke, Folker Hanefeld, \\ Wolfgang Hänicke, Klaus Dietmar Merboldt, and Jens Frahm
}

\begin{abstract}
Noninvasive studies of cerebral metabolism were performed with use of localized proton MR spectroscopy (MRS) in both healthy controls ( $\mathrm{n}=$ 4 , age 6 weeks to 2 years) and infants ( $n=4$, age $3-15$ months) who had impaired peroxisomal functions classified as variants of Zellweger syndrome. All patients revealed a marked decrease of $N$-acetylaspartate in white and gray matter, thalamus, and cerebellum, indicating impairment of normal neuronal development as well as neuronal loss. In two cases an increase of cerebral glutamine and a decrease of the cytosolic polyol myo-inositol in gray matter and striatum reflected the impact of a concomitant effect on hepatic function. Two cases 3 and 6 months of age exhibited a notable elevation of mobile lipids and/or cholesterol in white matter. These patients with severe disease died within 4 weeks after the MRS examination. While an increase of free fatty acids generally associated with a lysosomal storage disease was not consistently observed by proton MRS of brain, this technique provides a convenient and safe tool for the direct assessment of neuropathologic aspects of Zellweger syndrome such as neuronal degeneration, demyelination, and consequences of compromised liver function. Index Terms: Magnetic resonance, spectroscopy-Brain, metabolism-Zellweger syndrome-Infants.
\end{abstract}

The cerebrohepatorenal syndromes (CHRSs) of Zellweger, pseudo-Zellweger, and neonatal adrenoleukodystrophy are autosomal recessive disorders characterized by lack of peroxisomes or loss of peroxisomal functions (1-4). Metabolic alterations utilized for diagnosis of CHRSs include elevated very long chain fatty acids (VLCFAs) in the plasma and fibroblasts, impairment of plasmalogen biosynthesis, accumulation of pipecolic acid and phytanic acid, and abnormal patterns of bile acids. The pathology of the central nervous system reveals migrational disorders, storage of neutral fat in astrocytes and glycogen in cortical neurons, as well as cell degeneration and cell death indicated by cortical neuronal loss, fibrous gliosis, and lipid phagocytes.

From the Max-Planck-Institut für biophysikalische Chemie (H. Bruhn, W. Haenicke, K. D. Merboldt, and J. Frahm) and Abt. Kinderheilkunde, Schwerpunkt Neuropädiatrie, GeorgAugust-Universität (B. Kruse, G. C. Korenke, and F. Hanefeld), Göttingen, Germany. Address correspondence and reprint requests to $\mathrm{Dr}$. $\mathrm{H}$. Bruhn at Max-Planck-Institut für biophysikalische Chemie, Postfach 2841, D-3400 Göttingen, Germany.
Though MRI has been shown to be sensitive to the macroscopic histopathology involving polymicrogyria, pachygyria, heterotopia of gray matter, and hypomyelination (5), no information has hitherto been available about accompanying disturbances of cerebral metabolites. Recent advances in the ability of localized proton MR spectroscopy (MRS) to noninvasively examine an increasing number of metabolites in human brain in vivo offer new possibilities in this regard (6-9). The purpose of this work is to utilize proton MRS techniques for metabolic studies of both normal brain maturation in healthy controls and pathologic alterations in patients with CHRS.

\section{MATERIALS AND METHODS}

\section{MRS}

Integrated MRI/MRS examinations were carried out at 2.0 T using a conventional whole body system (Siemens Magnetom). Localization of 4 to 14 $\mathrm{ml}$ volumes of interest (VOIs) was achieved with 
use of short TE (TE $20 \mathrm{~ms}$ ) STEAM sequences (for experimental details see ref. 6). Following a fast scan MRI protocol comprising T1-weighted FLASH and T2-weighted CE-FAST images (10), proton MR spectra from different VOIs were acquired within measuring times of $6.5 \mathrm{~min}$ each (TR $3,000 \mathrm{~ms}, 128$ accumulations). Infants were investigated while sleeping following mild sedation with chloral hydrate. In all cases informed written consent was obtained from the parents. The total investigation time varied between 35 and $75 \mathrm{~min}$ for two to five different VOIs selected from midline gray matter, paraventricular white matter, thalamus, striatum, and cerebellum. Cessation of sedation and child movement eventually limited the number of accessible regions.

To facilitate spectral evaluations and comparisons, all proton MR spectra were processed and displayed in exactly the same way and scaled according to the size of the VOI. In fact, the use of short TEs (TE/T2 $0.05-0.10)$ and relatively long TRs (TR/T1 2-3) minimized T2 losses and T1 saturation effects, so that changes of resonance intensities (areas) with age or pathology became proportional to the respective metabolite concentrations. However, the evaluation of absolute concentrations (11) has been discarded here, since the heterogeneity of the subjects and the overall time span of the study would have required us to account for additional effects such as coil loading factors (head sizes) and changes in system performance with time. Instead, ratios of resonance intensities that eliminate the need for correction factors may serve as preliminary quantitative measures of relative concentration changes.

Although the number of patients and controls was limited in this study, the reliability of the spectra was supported by investigations of $>100$ children over the last 2 years carried out in this laboratory. In addition, multiple examinations of the same subject in this and other studies revealed excellent reproducibility $( \pm 5 \%)$, provided care was taken to match to VOI.

\section{CASE REPORTS}

Four patients with peroxisomal disorders (3-15 months old) were studied, two of them on different occasions with an interval of 3 months. In all infants diagnosis was established by biochemical investigation of peroxisomal functions. Relevant data are summarized in Table 1. Developmental changes in normal brain metabolism were investigated in a group of age-matched healthy controls.

\section{Case 1}

This girl had her first MRS examination at the age of 12 months. Elevated transaminases indicated liver involvement. At the time of her second MRS examination, she had been given a therapeutic regimen during the previous 3 months that included a restriction of VLCFAs and phytanic acid as well as supplementation of her diet with glyceroltrioleate and glyceroltrierucate. At this time she had signs of liver impairment. The thromboplastin time

TABLE 1. Clinical and biochemical data of four cerebrohepatorenal syndrome patients

\begin{tabular}{|c|c|c|c|c|}
\hline Case no./sex/age (mos) & Clinical data & Liver function & Peroxisomal function & MRS \\
\hline \multirow[t]{2}{*}{$\begin{array}{l}\text { 1/F/12 (Zellweger } \\
\text { variant) }\end{array}$} & \multirow[t]{2}{*}{$\begin{array}{l}\text { Muscular hypotonus, } \\
\text { nystagmus, retinitis } \\
\text { pigmentosa }\end{array}$} & $\begin{array}{l}\text { Before diet: ASAT } 242 \\
\text { U/L, ALAT } 132 \mathrm{U} / \mathrm{L} \text {, } \\
\text { ammonia normal }\end{array}$ & $\begin{array}{l}\text { VLCFA increased; } \\
\text { dicarbonic aciduria }\end{array}$ & $12 \mathrm{mos}$ \\
\hline & & $\begin{array}{l}\text { On diet: ASAT } 51 \mathrm{U} / \mathrm{L} \\
\text { ALAT } 8 \mathrm{U} / \mathrm{L} \\
\text { coagulopathy }\end{array}$ & $\begin{array}{l}\text { VLCFA increased, C26 } \\
\text { normal, C26:0/C22:0 still } \\
\text { increased }\end{array}$ & $15 \mathrm{mos}$ \\
\hline \multirow[t]{2}{*}{$\begin{array}{l}\text { 2/F/10 (pseudo-neonatal } \\
\text { ALD) }\end{array}$} & \multirow{2}{*}{$\begin{array}{l}\text { Seizures since birth, } \\
\text { severe hypotonia, } \\
\text { areflexia; CCT: } \\
\text { calcifications of basal } \\
\text { ganglia, white matter } \\
\text { hypodensities, recurrent } \\
\text { apnea; died at } 16 \text { mos }\end{array}$} & $\begin{array}{l}\text { Before diet: ammonia } \\
\text { increased }(56 \mu M) \text {, } \\
\text { otherwise normal }\end{array}$ & $\begin{array}{l}\text { VLCFA increased, acyl-coA } \\
\text { oxidase deficiency }\end{array}$ & 10 mos \\
\hline & & On diet: normal & & 13 mos \\
\hline 3/F/6 (Zellweger variant) & $\begin{array}{l}\text { Seizures since birth, } \\
\text { hypotonia, nystagmus, } \\
\text { facial dysmorphia, MRI: } \\
\text { bifrontal atrophy, } \\
\text { pachygyria; died at } 7 \\
\text { mos }\end{array}$ & $\begin{array}{l}\text { Hepatomegaly, ASAT } 94 \\
\text { U/L, ALAT } 64 \mathrm{U} / \mathrm{L}\end{array}$ & $\begin{array}{l}\text { VLCFA increased, } \\
\text { plasmalogen decreased in } \\
\text { erythrocytes, partial } \\
\text { deficiency of DHAP-AT in } \\
\text { thrombocytes }\end{array}$ & $6.5 \mathrm{mos}$ \\
\hline 4/F/3 (Zellweger) & $\begin{array}{l}\text { Seizures since birth, } \\
\text { hypotonia, nystagmus, } \\
\text { facial dysmorphia, } \\
\text { microcephaly; died at } 4 \\
\text { mos }\end{array}$ & $\begin{array}{l}\text { Mild hepatosplenomegaly, } \\
\text { otherwise normal }\end{array}$ & $\begin{array}{l}\text { VLCFA increased, } \\
\text { plasmalogen decreased in } \\
\text { erythrocytes }\end{array}$ & $3 \operatorname{mos}$ \\
\hline
\end{tabular}

ALD, adrenoleukodystrophy; ASAT, aspartate aminotransferase; ALAT, alanine aminotransferase; CT, computed tomography; VLCFA, very long chain fatty acids; DHAP-AT, acyl-CoA: dihydroxyacetone phosphate acyltransferase. 
was prolonged (Quick 41\%) as well as the partial thromboplastin (67 s) and the thrombin (20 s) time; the fibrinogen was normal. The long chain fatty acids still showed abnormal ratios: 0.076 for $\mathrm{C} 26 / \mathrm{C} 22$ (normal $0.013 \pm$ 0.009 ) and 0.98 for C24/C22 (normal $0.84 \pm 0.009$ ).

\section{Case 2}

This infant had a deficiency of acyl-coA oxidase. At the time of her first MRS examination at the age of 10 months, her liver function was normal apart from a slight increase of blood ammonia. At the time of her second MRS examination at the age of 13 months, she had been given the same diet as Case 1.

\section{Case 3}

This girl was of Afghan descent. At the time of the MRS examination at the age of 6.5 months, she was receiving phenobarbital $(52.5 \mathrm{mg} /$ day $)$ for a seizure disorder. Her liver was enlarged, the transaminases were slightly elevated, but her blood coagulation and ammonia were normal. Increased ratios of long chain fatty acids were 0.13 for $C 26 / 22$ and 1.33 for $C 24 / 22$. Plasmalogens were decreased in erythrocyte membranes. In thrombocytes a partial deficiency of acyl-CoA:dihydroxyacetone phosphate acyltransferase was found.

\section{Case 4}

This female infant had an MRS examination at the age of 3 months. Peroxisomal disorder was diagnosed soon after birth. She had elevated VLCFAs, low plasmalogens in erythrocytes, and a normal profile of bile acids. She received phenobarbital for seizures ( $15 \mathrm{mg}$ /day). Her liver enzymes were normal.

\section{RESULTS \\ Normal Cerebral Development}

Proton MR spectra of normal white and gray matter of a 4-month-old infant and a 2-year-old child are shown in Fig. 1. In agreement with previous studies (12), metabolite resonances were assigned to $\mathrm{N}$-acetylaspartate (NAA), glutamate (Glu), the creatine and phosphocreatine pool $(\mathrm{Cr})$, cholinecontaining compounds (Cho), and myo-inositol

FIG. 1. Metabolic changes during brain maturation as indicated by localized proton MR spectra (STEAM; TR $3,000 \mathrm{~ms}$; TE $20 \mathrm{~ms}$; TM $30 \mathrm{~ms} ; 128$ accumulations) of healthy controls. The spectra originate from parietal white matter of a 4-month-old infant using a $16 \times 30 \times 16 \mathrm{~mm}^{3}$ volume of interest (VOI) (a) and of a 2-year-old child $\left(20 \times 30 \times 20 \mathrm{~mm}^{3}\right.$ VOI). (b) Corresponding spectra from parietal midsagittal gray matter of the same controls were given from a $20 \times 30$ $\times 20 \mathrm{~mm}^{3}$ VOI (c) and from a $20 \times 30 \times 30 \mathrm{~mm}^{3}$ VOI (d) Resonances are assigned to $\mathrm{N}$-acetylaspartate (NAA), glutamate (Glu), creatine and phosphocreatine (Cr), cholinecontaining compounds (Cho), and myo-inositol (Ins).
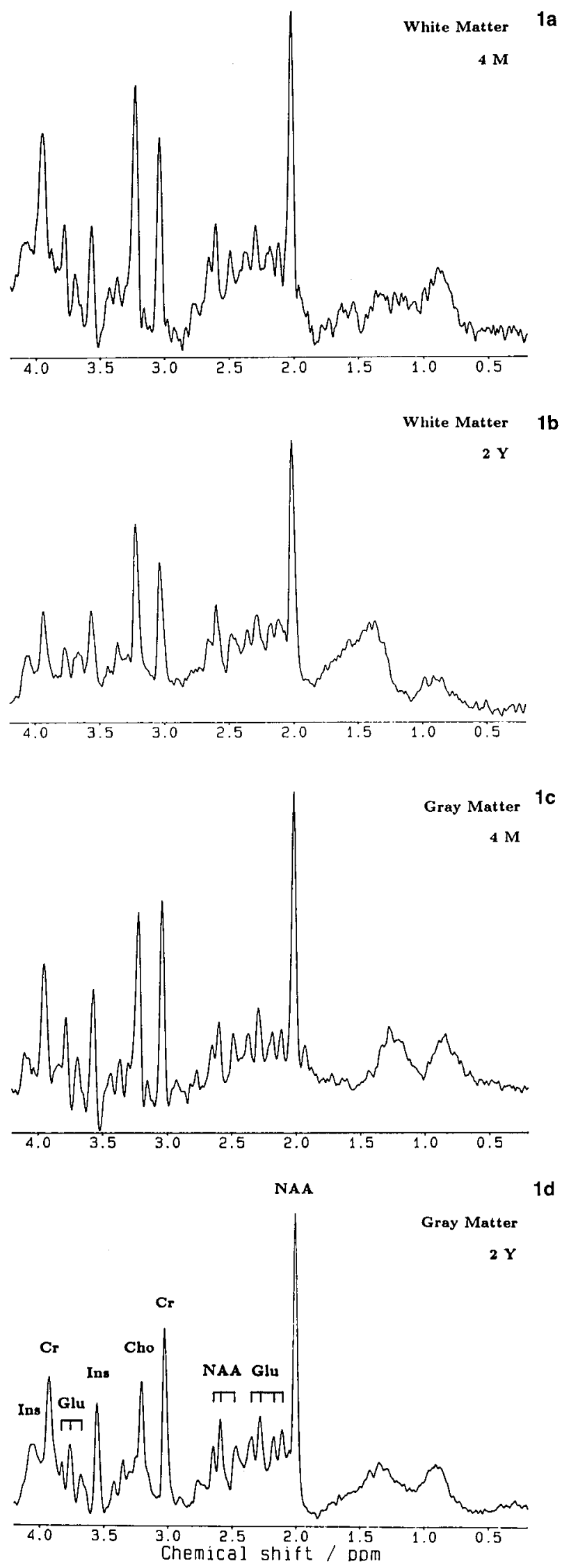
(Ins). The spectra demonstrate the extent of metabolic changes in the course of early brain maturation that have to be accounted for in the recognition of pathological changes in patients of similar age. The findings support previous data that are partly hampered by $\mathrm{T} 2$ attenuation (13-17).

The metabolite patterns revealed an increase of NAA and a decrease of Cho and Ins (relative to $\mathrm{Cr}$ ). Corresponding ratios of resonance intensities are summarized in Table 2. They include the data of another 4-month-old control as well as of a 6-weekold infant. Although the increase in the NAA/Cho ratio largely parallels myelination in all cerebral regions investigated, there are differences with respect to speed and extent. For example, the NAA/ Cho effect is much more pronounced in midsagittal parietal gray matter where values increase from 0.9 at 6 weeks to 1.5 at 4 months and 2.2 at 2 years than in parietal white matter with 1.0 at 6 weeks, 1.2 at 4 months, and 1.6 at 2 years. While the $\mathrm{Cr} / \mathrm{Cho}$ ratio stays about constant in white matter, gray matter values increase from 0.9 at 6 weeks to 1.4 at 2 years. myo-Inositol levels decrease from relatively high postnatal values until $\sim 4$ months as indicated by the variation of the $\mathrm{Cr} / \mathrm{Ins}$ ratios in white (and gray) matter from $1.1(1.0)$ at 6 weeks to $1.9(1.6)$ at 4 months and $1.8(1.5)$ at 2 years.

\section{Patients}

Proton MR spectra and corresponding images of Case 1 at 12 and 15 months are shown in Fig. 2. In comparison with controls, all patient spectra from locations in parietal white matter, right striatum, and parietal midsagittal gray matter revealed an overall decrease of NAA relative to both $\mathrm{Cr}$ and Cho. Respective metabolite ratios are summarized in Table 3 for all patients. For Case 1 the NAA/Cho

TABLE 2. Metabolite ratios from localized proton $M R$ spectra (TR/TE 3,000/20 ms) in different cerebral regions of healthy controls

\begin{tabular}{llcccc}
\hline $\begin{array}{l}\text { Control } \\
\text { no./age }\end{array}$ & Region & NAA/Cho & NAA/Cr & Cr/Cho & Cr/Ins \\
\hline 1/2 yrs & WM & 1.6 & 1.9 & 0.8 & 1.8 \\
& GM & 2.2 & 1.6 & 1.4 & 1.5 \\
& Thalamus & 1.4 & 1.3 & 1.1 & 2.3 \\
& Striatum & 1.7 & 1.1 & 1.5 & 3.0 \\
& Cerebellum & 1.0 & 1.0 & 1.0 & 1.7 \\
$2 / 4$ mos & WM & 1.2 & 1.5 & 0.8 & 1.8 \\
$3 / 4$ mos & WM 1 & 1.2 & 1.4 & 0.9 & 1.8 \\
& WM r & 1.2 & 1.3 & 0.9 & 2.0 \\
& GM & 1.5 & 1.4 & 1.1 & 1.6 \\
& Thalamus & 1.1 & 1.2 & 1.0 & 2.5 \\
$4 / 6$ wks & WM & 1.0 & 1.2 & 0.9 & 1.1 \\
& GM & 0.9 & 0.9 & 0.9 & 1.0 \\
& Thalamus & 1.0 & 1.0 & 1.0 & 1.8 \\
& Cerebellum & 0.7 & 0.6 & 1.2 & 1.2 \\
\hline
\end{tabular}

NAA, $N$-acetylaspartate; Cho, cholines; $\mathrm{Cr}$, creatine and phosphocreatine; Ins, myo-inositol; GM, parietal gray matter; WM, parietal white matter; $r$, right hemisphere; 1 , left hemisphere. and NAA/Cr values in white matter of 1.0 and 1.2 are identical to those of a 6-week-old infant, but well below the ratios of 1.6 and 1.9 obtained for a 2 -year-old child. A striking reduction of Ins in all three regions investigated is indicated by significantly higher $\mathrm{Cr} / \mathrm{Ins}$ ratios as compared with controls in the age range of 4 months to 2 years. For white matter the number is 3.1 as opposed to 1.8-2.0.

Detailed inspection of the coupled resonances in the 2.0 to $2.5 \mathrm{ppm}$ range of the spectra from gray matter and striatum (Fig. $2 b$ and c) resolves elevated contributions from glutamine. This point is further demonstrated in Fig. 3, which compares expanded chemical shift spectra from aqueous solutions of pertinent metabolites NAA, Glu, and Gln (Fig. 3a and $\mathrm{b}$ ) to a corresponding version of the gray matter spectrum of Case 1 (Fig. 3c). The addition of an equal amount of Gln (Fig. 3b) to a solution of equal concentrations of NAA and Glu (Fig. 3a) clearly identifies the additional resonance signals at 2.37 and $2.45 \mathrm{ppm}$ as strongly coupled multiplet lines from the $\gamma-\mathrm{CH}_{2}$ group of Gln (12). Since the primary resonances of the $\beta-\mathrm{CH}_{2}$ groups of Glu and Gln at 2.11 and $2.18 \mathrm{ppm}$ constructively overlap (Fig. 3b), and since the respective total signals of both Glu and Gln in Case 1 (Fig. 2b and c) are not higher than those of normal Glu alone (Fig. 1c and d), it can be estimated that roughly half of the Glu concentration has been changed into Gln in both gray matter and striatum.

Figure 4 shows proton MR spectra of white and gray matter of Case 2 studied at the age of 10 and 13 months. Though the images (not shown) revealed the absence of age-adequate myelination normally characterized by branching of white matter into gyri as well as deepened sulci (18), the spectra exhibited low absolute signal intensities that refer to a generalized decrease of metabolite concentrations by a factor of about two. The effect is most likely due to diminished cell populations. In addition, NAA was also markedly decreased relative to $\mathrm{Cr}$ and Cho. The corresponding NAA/Cho (and NAA/Cr) ratios in white matter of 0.6 (Table 3 ) are well below those of controls of $1.2(1.4)$ at 4 months and $1.6(1.9)$ at 2 years. The spectra at the follow-up three months after the first examination showed a very similar metabolic pattern. No improvement has been observed in these patients despite efforts to halt the neurodegenerative course by dietary means (19). As in Case 1 there was no objective beneficial effect of dietary treatment either with respect to the MRSdetectable metabolites or with regard to clinical improvement. The even further reduction of NAA and Ins in gray matter (cf. Fig. 4c and d) may be partially due to the fact that the use of a smaller VOI in the second study ( 8 vs. $18 \mathrm{ml}$ ) extracted a more specific loss of cortical neurons in gray matter as compared to axonal loss in white matter. 
$2 a$

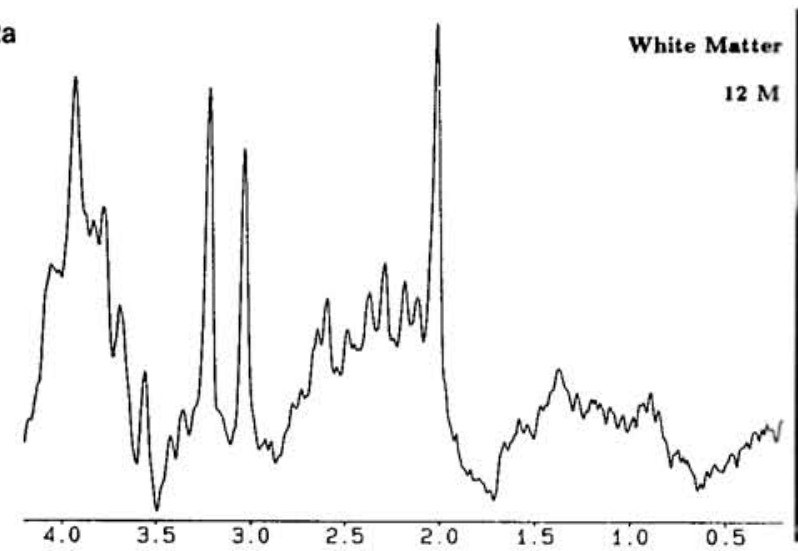

$2 b$

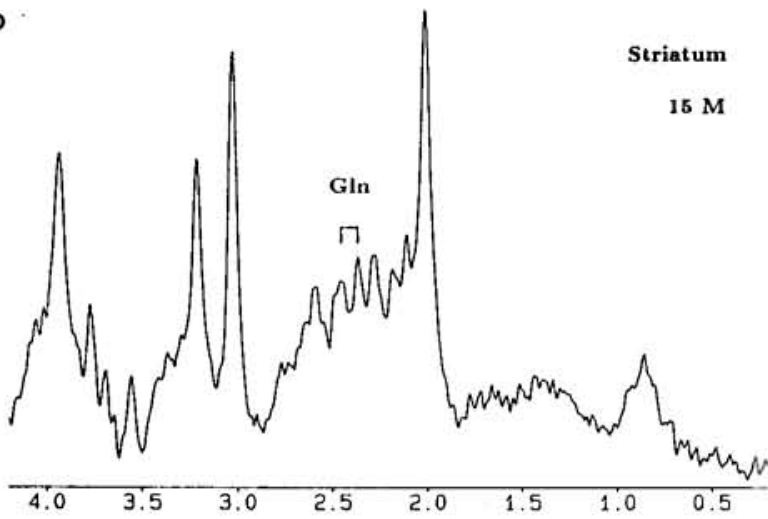

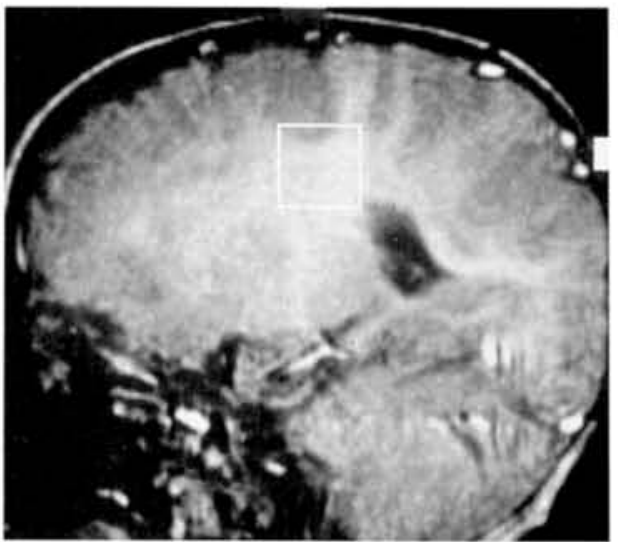

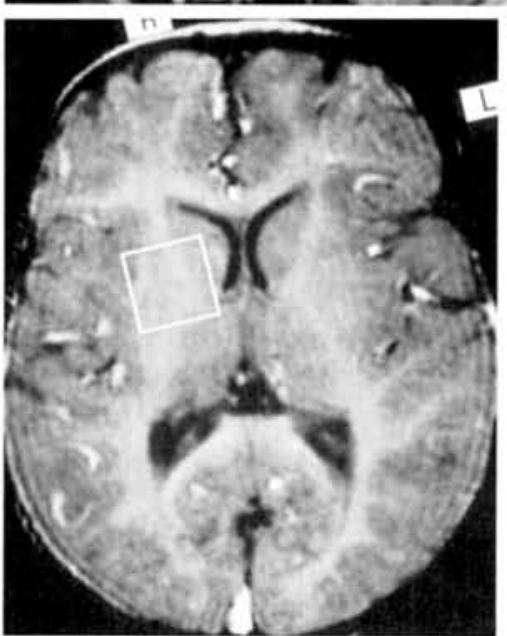

$2 \mathrm{e}$

2c

NAA
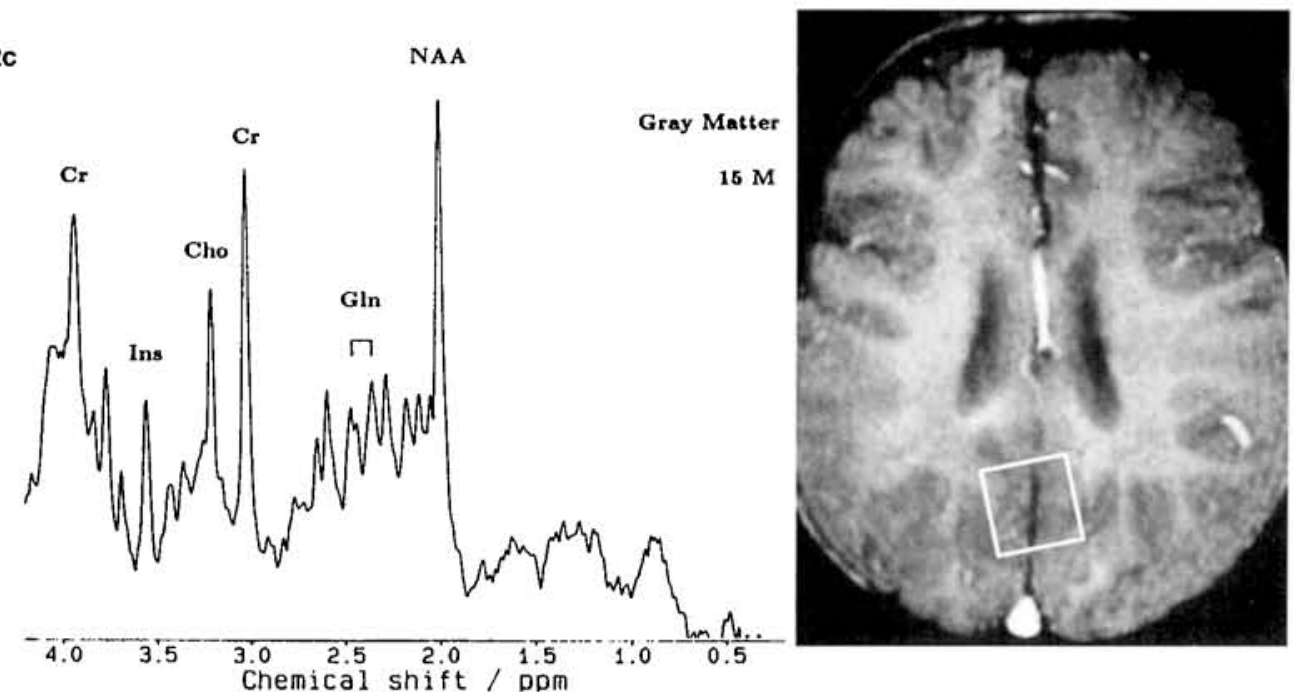

$2 f$

FIG. 2. Case 1: variant of Zellweger syndrome. Images taken at 12 and 15 months. Proton MR spectra $\left(20 \times 20 \times 20 \mathrm{~mm}{ }^{3} ;\right.$ other parameters as in Fig. 1) of parietal white matter (12 mos) (a), right striatum (15 mos) (b), and midsagittal parietal gray matter (15 mos) (c) demonstrate a decrease of $\mathrm{N}$-acetylaspartate (NAA) relative to control in all regions investigated. Decreased levels of myo-inositol (Ins) are seen in (a) and (b), while (b) and (c) exhibit increased contributions from glutamine (GIn). Corresponding T1-weighted fast scan MR images (multislice FLASH, TR/TE/ $\alpha=100 / 6 / 70^{\circ}$ ) are also shown (d-f), with boxes indicating the volume of interest selected for MRS. Cho, choline-containing compounds; $\mathrm{Cr}$, creatine and phosphocreatine. 
TABLE 3. Metabolite ratios from localized proton $M R$ spectra (TR/TE 3,000/20 ms) in different cerebral regions of patients who had cerebrohepatorenal syndrome

\begin{tabular}{cclcccc}
\hline $\begin{array}{c}\text { Case } \\
\text { no. }\end{array}$ & $\begin{array}{c}\text { Age } \\
\text { (mos) }\end{array}$ & Region & NAA/Cho & NAA/Cr & Cr/Cho & Cr/Ins \\
\hline 1 & 12 & WM & 1.0 & 1.2 & 0.9 & 3.1 \\
& 15 & GM & 1.9 & 1.0 & 1.8 & 2.2 \\
& 15 & Striatum & 1.5 & 0.9 & 1.6 & 4.3 \\
2 & 10 & WM & 0.6 & 0.6 & 1.0 & 1.8 \\
& 13 & WM r & 0.5 & 0.5 & 1.0 & 1.8 \\
& 13 & WM 1 & 0.5 & 0.5 & 1.0 & 2.0 \\
& 10 & GM & 1.2 & 0.8 & 1.5 & 2.0 \\
& 13 & GM & 0.8 & 0.6 & 1.3 & 2.4 \\
& 10 & Thalamus & 1.0 & 1.0 & 1.0 & 2.8 \\
& 6.5 & WM & 0.6 & 0.6 & 1.0 & 2.3 \\
& & GM & 0.7 & 0.7 & 1.1 & 1.8 \\
& & Thalamus & 0.7 & 0.7 & 1.1 & 2.5 \\
4 & 3 & Cerebellum & 0.5 & 0.5 & 1.1 & 2.5 \\
& & WM & 0.6 & 0.7 & 0.9 & 1.8 \\
& & GM & 0.7 & 0.7 & 1.0 & 1.3 \\
& & Thalamus & 0.8 & 0.9 & 0.9 & 2.1 \\
& & Cerebellum & 0.5 & 0.6 & 0.9 & 1.5 \\
\hline
\end{tabular}

For abbreviations see Table 2.

Proton MR spectra and images of Case 3 at the age of 6.5 months are shown in Fig. 5. Although the images indicated no significant delay in myelination, spectra from white matter, cerebellum, thalamus, and gray matter again revealed a decrease of NAA from locations not affected by pachygyria. As in the previous case, the NAA/Cho and NAA/Cr ratios for white and gray matter (Table 3) are 0.6 and 0.7 , which is a factor of two below those of the 4-month-old control subjects (Table 2). In addition, and in contrast to the findings for the two older Cases 1 and 2, the spectra from white matter and, to a smaller degree, from thalamus displayed intense resonances at 0.87 and $1.27 \mathrm{ppm}$ that are characteristic for the $\mathrm{CH}_{2}$ and $\mathrm{CH}_{3}$ residues of mobile lipids. However, since the relatively high intensity of the $0.87 \mathrm{ppm}$ signal indicates the presence of cholesterol, it is difficult to estimate the average chain length of the contributing free fatty acids. The intensities of similar aliphatic resonances in spectra from gray matter and thalamus must be considered as normal when compared with the results of controls in Fig. 1. Although not specifically indicated in the spectra of Fig. 5, there was a slight increase of Gln in gray matter (Fig. 5d) as well as of lactate in the thalamus (Fig. 5c; $1.33 \mathrm{ppm}$ doublet with a $7 \mathrm{~Hz}$ spin-spin splitting). The Ins signal was not as low as for Case 1 but showed a notable decrease in white and gray matter when compared with controls, i.e., high $\mathrm{Cr} / \mathrm{Ins}$ ratios in Table 3.

Figure 6 shows proton MR spectra and images of Case 4 at the age of 3 months. The observations are in close agreement with the findings for Case 3 in similar locations of the brain. All spectra exhibited low NAA signals yielding NAA/Cho and NAA/Cr ratios in white and gray matter that are identical to
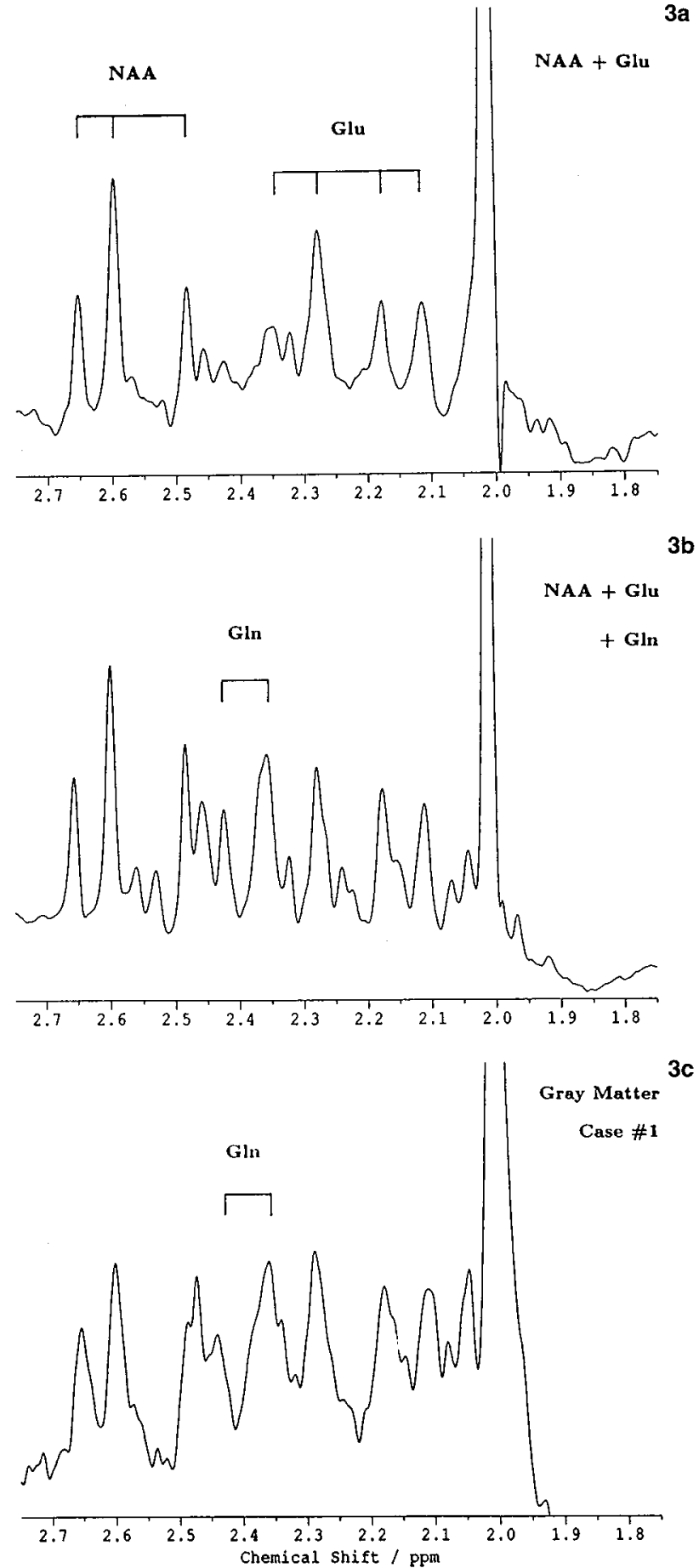

FIG. 3. Contributions from increased glutamine (GIn) are demonstrated by a comparison of proton MR spectra (parameters as in Fig. 2) of aqueous solutions of equal concentrations of $\mathrm{N}$-acetylaspartate (NAA) and glutamate (Glu) (a), equal concentrations of NAA, Glu, and GIn (b), and the gray matter spectrum of Case 1 shown in Fig. 2c (c). All spectra are expanded horizontally $(1.75-2.75 \mathrm{ppm})$ and vertically to simplify inspection of the additional resonances from GIn, e.g., appearing at 2.37 and $2.45 \mathrm{ppm}$. 


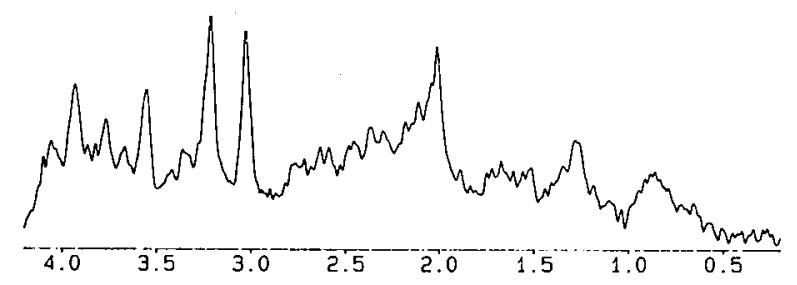

$4 b$

White Matter $13 \mathrm{M}$

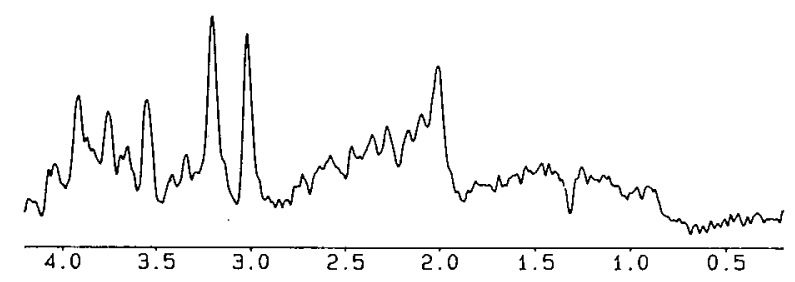

$4 c$

Gray Matter

$10 \mathrm{M}$

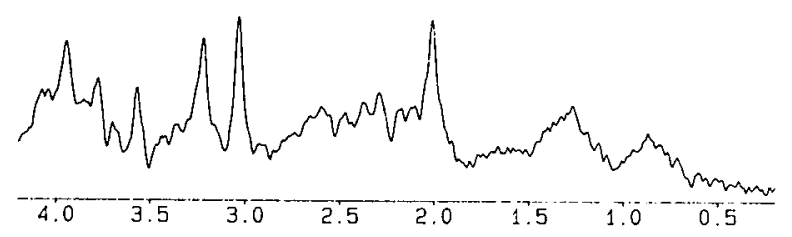

4d

Gray Matter

$13 \mathrm{M}$

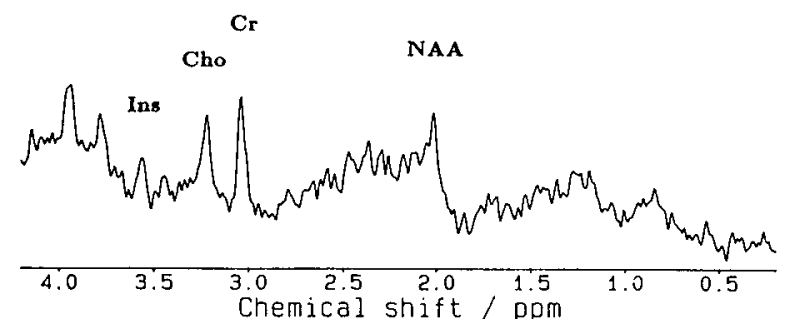

FIG. 4. Case 2: pseudo-neonatal adrenoleukodystrophy. Images taken at 10 and 13 months. Proton MR spectra of parietal white matter at 10 months $\left(16 \times 30 \times 20 \mathrm{~mm}^{3}\right.$; other parameters as in Fig. 2) (a) and at 13 months $(20 \times 30 \times 20$ $\left.\mathrm{mm}^{3}\right)($ b) and of midsagittal gray matter at 10 months $(20 \times 30$ $\left.\times 30 \mathrm{~mm}^{3}\right)$ (c) and at 13 months $\left(20 \times 20 \times 20 \mathrm{~mm}^{3}\right)$ (d). The spectra demonstrate an absolute decrease of all metabolite levels as well as a further reduction of $\mathrm{N}$-acetylaspartate relative to creatines and cholines. Cho, choline-containing compounds; $\mathrm{Cr}$, creatine and phosphocreatine; Ins, myoinositol.

those of Cases 2 and 3 (Table 3). As in the previous 6-month-old patient, elevated aliphatic resonances from lipids and/or cholesterol appeared in white matter and thalamus.

\section{DISCUSSION}

Alterations of cerebral metabolites that can be monitored by localized proton MRS in vivo relate to different pathogenetic mechanisms. Direct consequences of impaired peroxisomal function were most evident as an absolute and relative decrease of NAA in all cases studied. This decrease was most prominent in cortical white and gray matter. While $\mathrm{NAA} / \mathrm{Cho}$ and NAA/Cr ratios were reduced by factors of two to three as compared with controls, the absolute loss of NAA may be estimated to range from $30 \%$ (Case 1) to $90 \%$ (Case 2). In brain tissue NAA is located in neurons (20), as suggested by its absence in gliomas (8) and its decrease in a large number of pathologic states as first noted in acute stroke (21). Therefore, a reduction of the NAA resonance signal appears to reflect the extent of neuronal degeneration or loss. At present it is not clear whether the observed neuronal damage is a consequence of demyelination or of enzymatic deficiency in neurons or both.

The finding of increased aliphatic hydrocarbon resonances in the two younger patients (3 and 6 months of age) was striking in white matter and less pronounced in the thalamus. Conspicuously, there might be a correlation with the clinical status as these patients died early within 4 weeks after the MRS examination. Furthermore, it is of interest to note that plasmalogens were decreased in these patients in agreement with observations of a reduced stability of plasmalogens in erythrocytes in CHRS patients under 6 months of age (19). Although the spectral consequences of changes in cerebral plasmalogen concentrations at this stage remain speculative, contributions from breakdown products of myelin may be reflected in the increased hydrocarbon resonances. The observation of mobile lipids in white matter may also be related to histopathologic studies reporting neural parenchyma in CHRS patients to contain lipid-laden astrocytes (neutral fat) and phagocytes (foam cells). In addition, an increase of cholesterol esters and VLCFAs by the impaired catabolism of cholesterol to bile acids might contribute to the MRS observation.

A general or dramatic increase of cerebral lactate was not observed in CHRS. Slightly elevated lactate levels in the younger patients hint at an increased "aerobic" glycolysis in these cases. Loosened coupling between oxidative phosphorylation and electron transport in the respiratory chain has been postulated to explain the mitochondrial impairment secondary to peroxisomal deficiency (22).

The involvement of internal organs in the course of the disease is demonstrated by Case 1 where liver impairment as evidenced by serum data bear on cerebral metabolite levels. Although blood ammonia was still in the upper normal range, the cerebral increase of Gln and decrease of Ins were similar to 
$5 a$

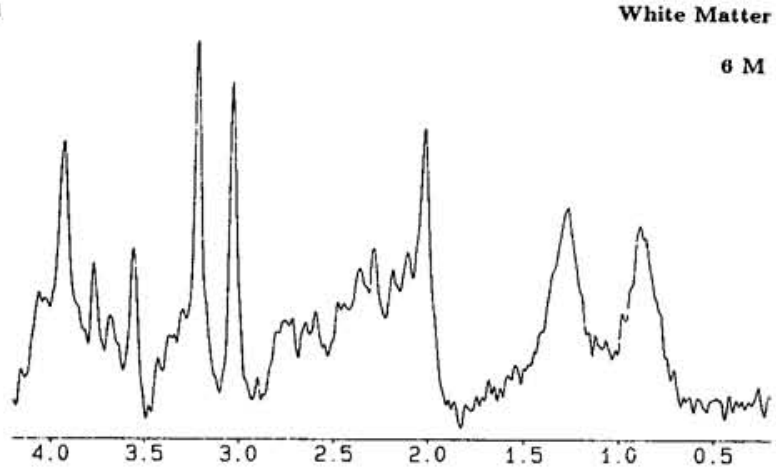

$5 b$

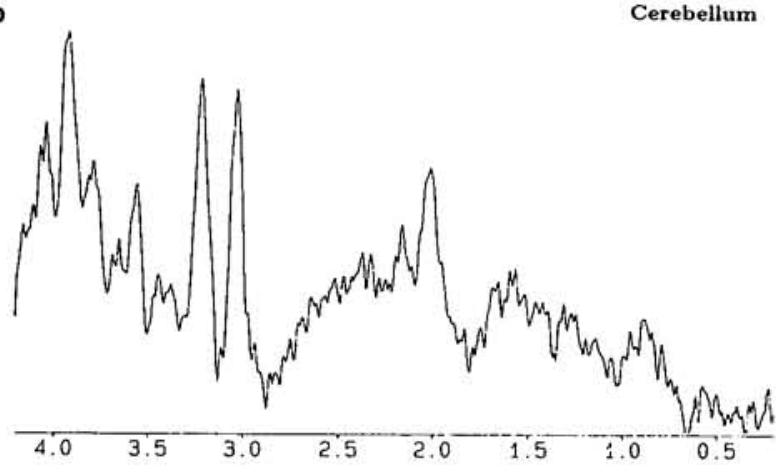

$5 c$

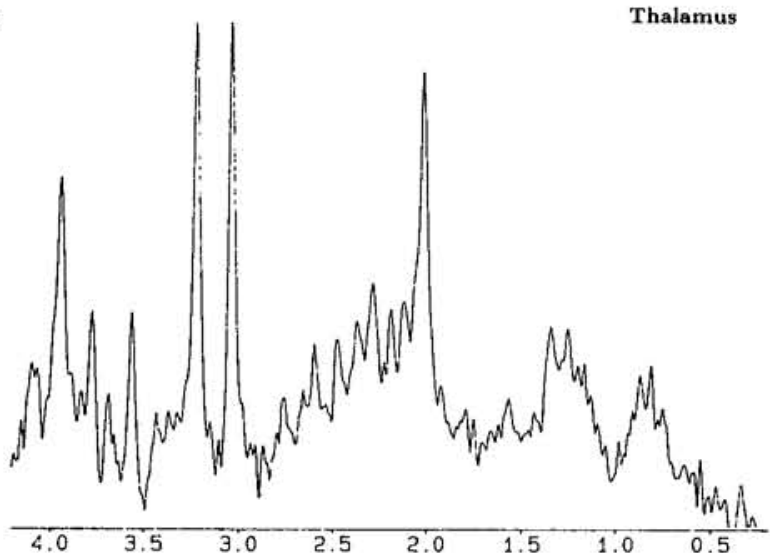

$5 d$

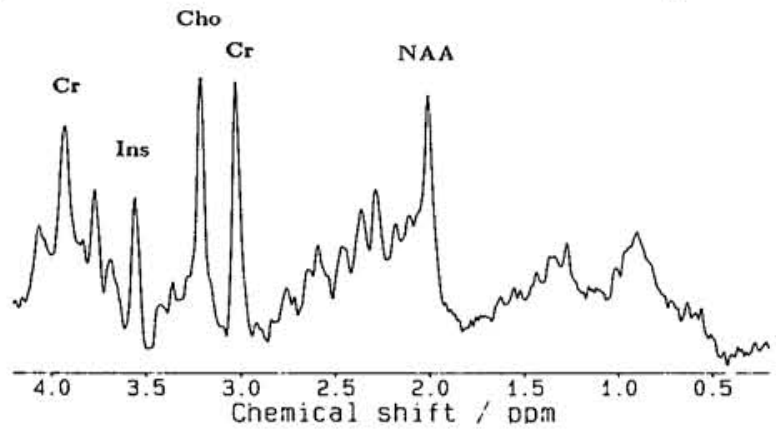

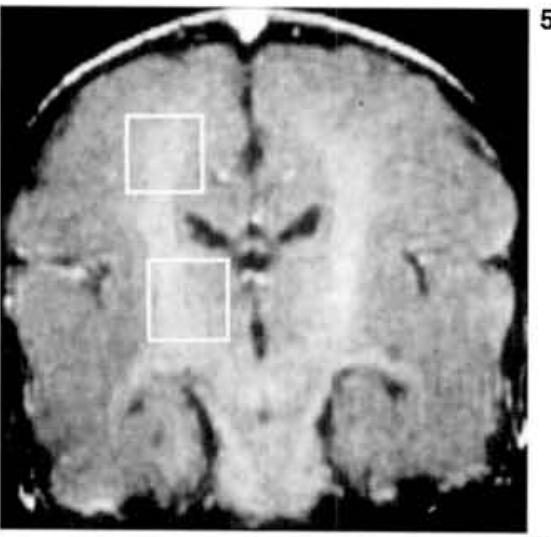

$5 e$

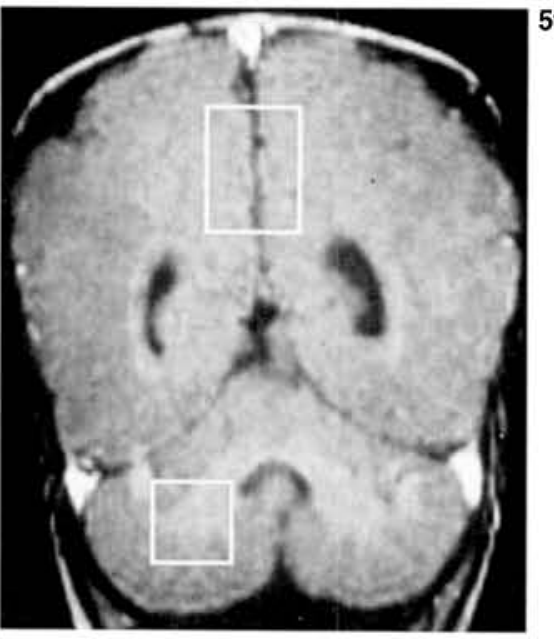

FIG. 5. Case 3: variant of Zellweger syndrome. Images taken at 6.5 months. Proton MR spectra of parietal white matter $\left(16 \times 30 \times 16 \mathrm{~mm}^{3}\right)(a)$, right cerebellum $\left(16 \times 16 \times 16 \mathrm{~mm}^{3}\right)$ (b), right thalamus $\left(16 \times 16 \times 16 \mathrm{~mm}^{3}\right)$ (c), and midsagittal parietal gray matter $\left(16 \times 25 \times 25 \mathrm{~mm}^{3}\right)(\mathrm{d})$. The spectra reveal a generalized neuronal damage and an increase of free fatty acids in white matter. Also shown are corresponding T1-weighted FLASH MR mages (e and $\mathbf{f}$ ). All parameters as in Fig. 2. 
$6 a$

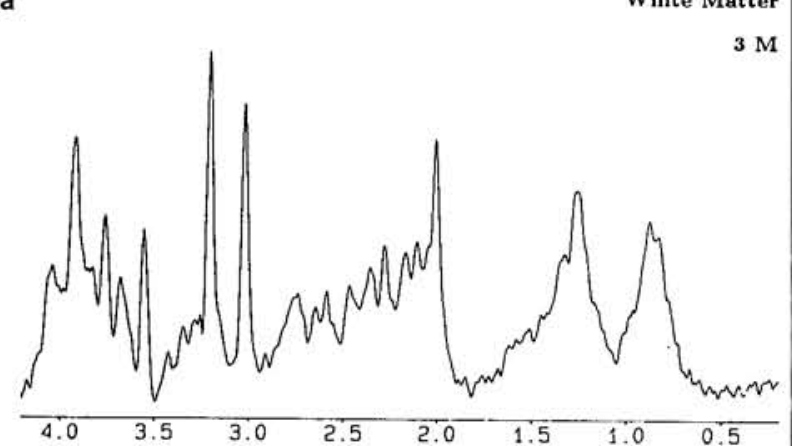

$6 b$
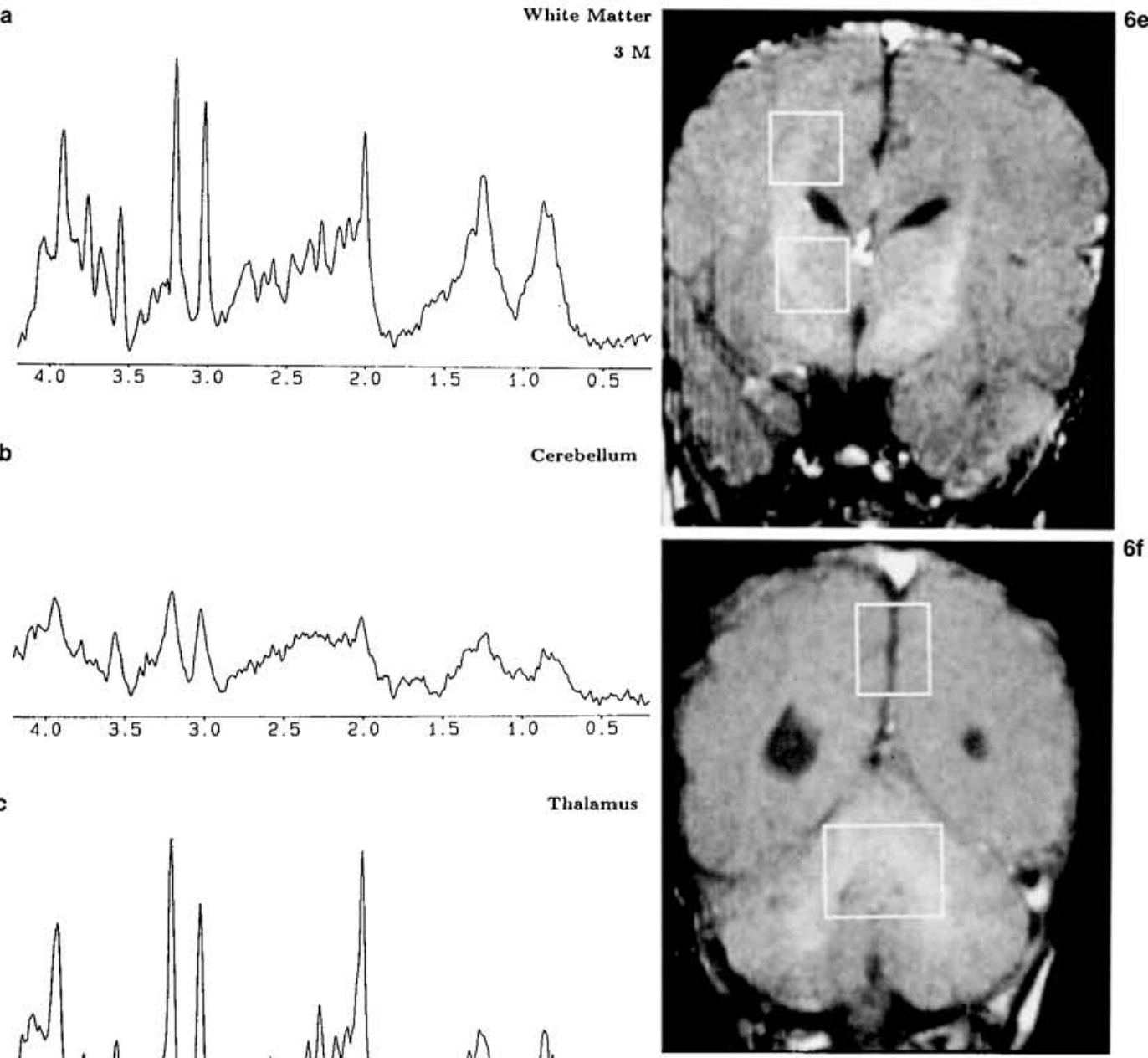

$6 c$

Thalamus

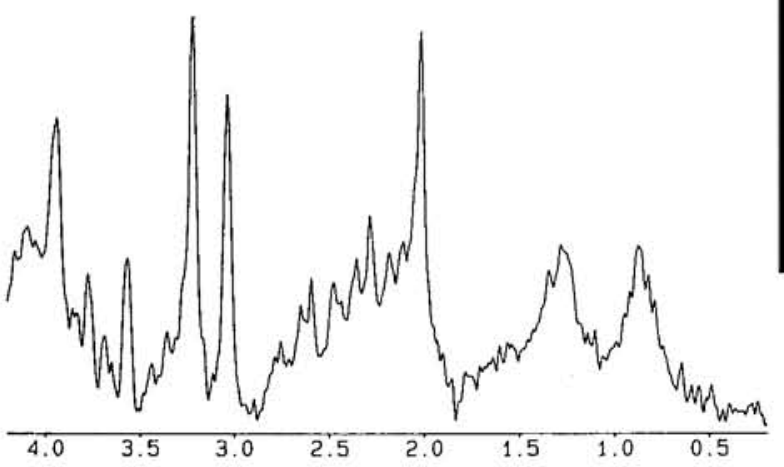

$6 d$

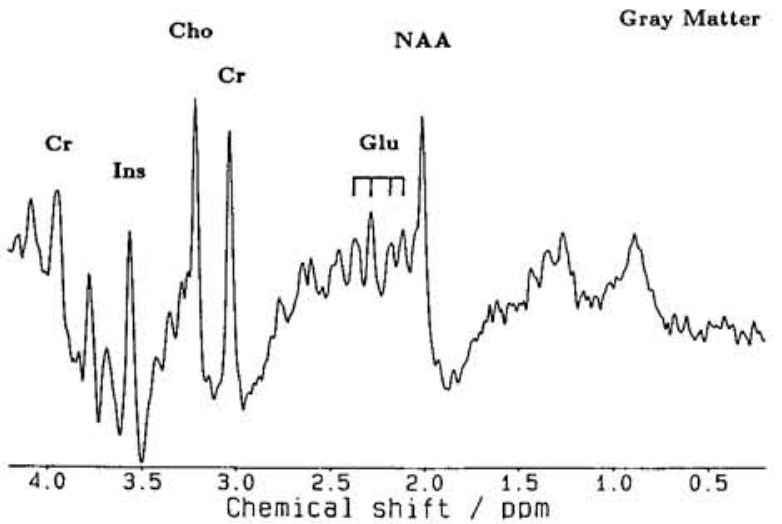

FIG. 6. Case 4: Zellweger syndrome. Images taken at 3 months. Proton MR spectra of parietal white matter $(16 \times$ $\left.30 \times 16 \mathrm{~mm}^{3}\right)(a)$, midcerebellum $(20 \times$ $\left.20 \times 20 \mathrm{~mm}^{3}\right)(\mathrm{b})$, right thalamus $(16 \times$ $\left.16 \times 16 \mathrm{~mm}^{3}\right)(\mathrm{c})$, and midsagittal parietal gray matter $\left(16 \times 20 \times 20 \mathrm{~mm}^{3}\right)$ (d). The spectra exhibit a similar metabolite pattern as observed for Case 3 in Fig. 5. Also shown are corresponding T1-weighted FLASH MR images (e and f). All parameters as in Fig. 2. 
observations in proton MR spectra of patients with hepatic encephalopathy (23) or liver cirrhosis (24).

\section{CONCLUSION}

Proton MRS studies of cerebral metabolites in patients with CHRS revealed a number of disturbances that are associated with neuronal and axonal degeneration, demyelination, and compromised liver function. Although the present findings are not specific for peroxisomal dysfunction, they provide unique insights into pathologic alterations of brain metabolism that lead to objective measures for the metabolic involvement of cerebral tissue in CHRS otherwise not available. The ability to perform repeated examinations demonstrates the potential of MRS in the control of therapeutic trials. Applications of proton MRS in the field of neuropediatrics are expected to further develop as a noninvasive tool for metabolic studies complementary to MRI.

Acknowledgment: Financial support by the Bundesminister für Forschung und Technologie of the Federal Republic of Germany (grant 01 VF 8606/6) is gratefully acknowledged. Drs. D. H. Hunneman (Göttingen), A. Roscher (München), and R. B. H. Schutgens and R. J. A. Wanders (Amsterdam) performed the studies for VLCFAs and peroxisomal functions.

\section{REFERENCES}

1. Kelley R. Review: the cerebrohepatorenal syndrome of Zellweger. Morphologic and metabolic aspects. Am J Med Genet 1983;16:503-17.

2. Moser AE, Singh I, Brown FR, et al. The cerebrohepatorenal (Zellweger) syndrome. Increased levels and impaired degradation of very-long-chain fatty acids and their use in prenatal diagnosis. $N$ Engl J Med 1984;310:1141-6.

3. Wanders RJA, Heymans HSA, Schutgens RBH, Barth PG, van den Bosch H, Tager JM. Peroxisomal disorders in neurology. J Neurol Sci 1988;88:1-39.

4. Schutgens RBH, Wanders RJA. Peroxisomale StörungenBiochemische Aspekte. In: Hanefeld F, Rating D, Christen $\mathrm{HJ}$, eds. Aktuelle neuropādiatrie 1989. Heidelberg: Springer, 1990:145-58.

5. Van der Knaap MS, Valk J. The MR spectrum of peroxisomal disorders. Neuroradiology 1991;33:30-7.

6. Frahm J, Michaelis T, Merboldt KD, Bruhn H, Gyngell ML, Hänicke W. Improvements in localized proton NMR spectroscopy of human brain. Water suppression, short echo times, and $1 \mathrm{ml}$ resolution. J Magn Res 1990;90:464-73.

7. Bruhn H, Wilichowski E, Hanefeld F, Merboldt KD, Michaelis T, Frahm J. Cerebral findings in children with mitochondrial disorders. Metabolic disturbances detected by localized proton MRS. Society of Magnetic Resonance in Medicine Tenth Annual Meeting, August 10-16, 1991, San Francisco, p 192.

8. Frahm J, Bruhn H, Hänicke W, Merboldt KD, Mursch K, Markakis E. Localized proton NMR spectroscopy of brain tumors, using short-echo time STEAM sequences. $J$ Comput Assist Tomogr 1991;15:915-22.

9. Bruhn H, Frahm J, Merboldt KD, et al. Multiple sclerosis in children. Cerebral metabolic alterations monitored by localized proton magnetic resonance spectroscopy in vivo. Ann Neurol 1992 (in press).

10. Frahm J, Gyngell ML, Hänicke W. Rapid scan techniques. In: Stark DD, Bradley WG, eds. Magnetic resonance imaging. 2nd ed. St. Louis: Mosby, 1991:165-203.

11. Michaelis T, Bruhn H, Hänicke W, Gyngell ML, Merboldt KD, Frahm J. Quantification of cerebral metabolites in man. Results using short-echo time localized proton MRS. Society of Magnetic Resonance in Medicine Tenth Annual Meeting, August 10-16, 1991, San Francisco, p 387.

12. Michaelis T, Merboldt KD, Hänicke W, Gyngell ML, Bruhn $\mathrm{H}$, Frahm J. On the identification of cerebral metabolites in localized ${ }^{1} \mathrm{H}$ NMR spectra of human brain in vivo. $N M R$ Biomed 1991;4:90-8.

13. Van der Knaap MS, van der Grond J, van Rijen PC, Faber JAJ, Valk J, Willemse K. Age-dependent changes in localized proton and phosphorus MR spectroscopy of the brain. Radiology 1990;176:509-15.

14. Connelly A, Austin SJ, Gadian DG. Localized 'H MRS in the paediatric brain: age and regional dependence. Society of Magnetic Resonance in Medicine Tenth Annual Meeting, August 10-16, 1991, San Francisco, p 379.

15. Hūppi PS, Posse $S$, Lazeyras F, et al. Brain development in preterm and term babies studied with ${ }^{1} \mathrm{H}$ magnetic resonance spectroscopy using short-echo time STEAM technique. Society of Magnetic Resonance in Medicine Tenth Annual Meeting, August 10-16, 1991, San Francisco, p 377.

16. McGowan JC, DiGiacomo JE, Cortey A, Lenkinski RE, Delivoria-Papadopoulos $\mathrm{M}$. Investigation of neonatal cerebral metabolism and function by proton magnetic resonance spectroscopy. Society of Magnetic Resonance in Medicine Tenth Annual Meeting, August 10-16, 1991, San Francisco, p 378.

17. Peden CJ, Cowan FM, Bryant DJ, et al. Proton MR spectroscopy of the brain in infants. $J$ Comput Assist Tomogr 1991;14:886-94.

18. Salamon G, Raynaud C, Regis J, Rumeau C. Magnetic resonance imaging of the pediatric brain. 1st ed. New York: Raven Press, 1990.

19. Schutgens RBH, Wanders RJA, Heymans HSA, et al. Zellweger syndrome: biochemical procedures in diagnosis, prevention and treatment. J Inher Metab Dis 1987;10(suppl 1): $33-45$.

20. Birken DL, Oldendorf WH. $N$-Acetylaspartic acid: a literature review of a compound prominent in ${ }^{1} \mathrm{H}-\mathrm{NMR}$ spectroscopic studies of brain. Neurosci Biobehav Rev 1989;13:2331.

21. Bruhn H, Frahm J, Gyngell ML, Merboldt KD, Hänicke W, Sauter R. Cerebral metabolism in man after acute stroke: new observations using localized proton NMR spectroscopy. Magn Res Med 1989;9:126-31.

22. Goldfischer $\mathrm{S}$, Moore $\mathrm{CL}$, Johnson $\mathrm{AB}$, et al. Peroxisomal and mitochondrial defects in the cerebro-hepato-renal syndrome. Science 1973;182:62-4.

23. Kreis R, Farrow N, Ross BD. Diagnosis of hepatic encephalopathy by proton magnetic resonance spectroscopy. Lancet 1990;336:635-36.

24. Bruhn H, Merboldt KD, Michaelis T, et al. Proton MRS of metabolic disturbances in the brain of patients with liver cirrhosis and subclinical hepatic encephalopathy. Society of Magnetic Resonance in Medicine Tenth Annual Meeting, August 10-16, 1991, San Francisco, p 400. 